\title{
Studies on the Psychological Health Status for Bi-disadvantaged Students in Secondary Vocational Schools and Its Countermeasures
}

\author{
Qiuwei Jiang and Qiangwei Yan ${ }^{\text {a, * }}$ \\ Wuhan Textile University, Wuhan 430200, China \\ ayan.wuse@aliyun.com \\ ${ }^{*}$ Corresponding author: Qiangwei Yan
}

Keywords: Secondary vocational school, Bi-disadvantaged Students, Psychological Health.

\begin{abstract}
The students who face the economic difficulties and academic difficulties caused by community are called "Bi disadvantaged students", family and individual factors. The paper takes Bi-disadvantaged Students in Secondary Vocational Schools as the research object, on the basis of psychological measurement and investigation interview of Bi-disadvantaged Students in Secondary Vocational Schools, the status of psychological health of those students are discussed, in order to provide theoretical bases for the poor students' psychological work.
\end{abstract}

\section{Introduction}

With the development of social economy, the gap between the rich and the poor has increased, and the phenomenon of economic difficulties, learning difficulties and psychological confusion in the secondary vocational school students has attracted more and more attention. The students who face the dual pressure of economic and academic difficulties caused by the factors such as the social, family and students themselves are who we call the Bi-disadvantaged students. The psychological pressure those students bear is much heavier than non-Bi-disadvantaged students or the students who face one kind of difficult. And they have more psychological problems, therefore paying more attention to this group is an essential part of secondary vocational school students' psychological health education.

\section{Research contents and methods}

\subsection{Research contents.}

Based on psychological measurement and survey interview, this article analyzes the psychological health status of Bi-disadvantaged students in secondary vocational schools(BSISVS).Combining theory with practice, taking several aspects such as psychological health status analysis of those students and the countermeasure research on as the breakthrough point, in-depth analysis on psychological characteristics of BSISVS, and then discuss the rules from special to general, which has universal significance and countermeasures.

\subsection{Research methods.}

The research methods of this paper are as follows: literature, data method, psychological measurement and interview. $480 \mathrm{Bi}$-disadvantaged students are selected from 5 secondary vocational schools in Wuhan city, including 252 boys and 228 girls. The Bi-disadvantaged students' selection criteria is that choosing the students with learning difficulty from poor students in the library. Learning difficulty is a phenomenon that exists in all kinds of schools. There are many definitions of learning difficulties at home and abroad, but there is no uniform definition. With the present situation of our educational and academic circles on the definition of learning difficulties, and the actual situation of 5 secondary vocational schools, our research makes several main criteria choosing the students with learning difficulties from poor students in the library: first, the one with normal intelligence, and learning difficulties caused by physical defects; second, the one with poor academic performance, unable to meet the requirements of teaching for a long time and ranking behind in 
comprehensive learning in a class; third, the one from comprehensive evaluation of teachers and head teachers.

We use SCL90 symptom checklist to evaluate the level of the Bi-disadvantaged students' psychological health in this research. We interview different students to further knowledge of the Bi-disadvantaged students' actual situations. Then we sum up to provide the basis on developing effective psychological problems intervention measures for them.

\section{Research result}

\subsection{The distribution of the SCL90 test results of BSISVS.}

The table1 shows that the number of BSISVS who have psychological problems is large. There are 232 people who have positive symptoms, accounting for $47.97 \%$; there are 109 people with severe psychological problems, accounting for $22.8 \%$.Generally speaking, there is no gender difference.

Table 1. The distribution of the SCL90 test results of BSISVS [ $\left.{ }^{n}(\%)\right]$

\begin{tabular}{|c|c|c|c|}
\hline Project & $\begin{array}{c}\text { Bi-disadvantaged } \\
\text { students }(\mathrm{n}=480)\end{array}$ & Male (n=252) & Female (n=228) \\
\hline $\begin{array}{c}\text { The one has obvious psychological } \\
\text { problems and need psychological } \\
\text { counseling as soon as possible }\end{array}$ & $109(22.8)$ & $57(22.56)$ & $53(23.11)$ \\
\hline $\begin{array}{c}\text { The one may has psychological } \\
\text { problems and should be concerned }\end{array}$ & $123(25.6)$ & $66(26.11)$ & $57(24.86)$ \\
\hline The one with psychological health & $248(51.6)$ & $129(51.33)$ & $118(52.03)$ \\
\hline
\end{tabular}

3.2 The comparison of Bi-disadvantaged students and Non-Bi-disadvantaged students in secondary vocational school.

Seen from table 2, we can see that except for somatization and other two aspects where Bi-disadvantaged students and non-Bi-disadvantaged students in secondary vocational schools don't have obvious difference, in other projects were all higher than those of poor students non psychologically poor students, among which the scores of compulsion, interpersonal relationship, anxiety, hostility, phobia, paranoia, psychosis factor are significantly higher than those of non-Bi-disadvantaged students in secondary vocational school .

Table 2. The comparison of Bi-disadvantaged students and Non-Bi-disadvantaged students in secondary vocational school with SCL-90

\begin{tabular}{|c|c|c|c|c|}
\hline Factors & $\begin{array}{c}\text { Bi-disadvantaged } \\
\text { students }(\mathrm{n}=480)\end{array}$ & $\begin{array}{c}\text { Non-Bi-disadvantaged } \\
\text { students(n=500) }\end{array}$ & $\mathrm{t}$ & $\mathrm{p}$ \\
\hline somatization & $1.37 \pm 0.43$ & $1.37 \pm 0.45$ & 0.15 & $\mathrm{p}>0.05$ \\
\hline $\begin{array}{c}\text { Obsessive } \\
\text { compulsive } \\
\text { symptoms }\end{array}$ & $1.90 \pm 0.55$ & $1.62 \pm 0.61$ & 5.60 & $\mathrm{p}<0.01$ \\
\hline $\begin{array}{c}\text { interpersonal } \\
\text { relationship }\end{array}$ & $1.97 \pm 0.64$ & $1.67 \pm 0.62$ & 3.13 & $\mathrm{p}<0.01$ \\
\hline depression & $1.85 \pm 0.63$ & $1.51 \pm 0.61$ & 1.98 & $\mathrm{p}<0.05$ \\
\hline dysphoria & $1.58 \pm 0.60$ & $1.39 \pm 0.42$ & 3.81 & $\mathrm{p}<0.01$ \\
\hline hostile & $1.87 \pm 0.69$ & $1.47 \pm 0.57$ & 4.35 & $\mathrm{p}<0.01$ \\
\hline terror & $1.68 \pm 0.61$ & $1.47 \pm 0.49$ & 9.07 & $\mathrm{p}<0.01$ \\
\hline crankiness & $1.81 \pm 0.64$ & $1.73 \pm 0.60$ & 3.56 & $\mathrm{p}<0.01$ \\
\hline psychoticism & $1.54 \pm 0.51$ & $1.36 \pm 0.47$ & 4.51 & $\mathrm{p}<0.01$ \\
\hline others & $1.55 \pm 0.49$ & $1.48 \pm 0.45$ & 1.60 & $\mathrm{p}>0.05$ \\
\hline
\end{tabular}

$\mathrm{P}>0.05$ indicated that the difference was not obvious; $\mathrm{P}<0.05$ showed significant difference; $\mathrm{P}<0.01$ showed extraordinary difference 
According to the interview, the factors affecting the psychological health of BSISVS are complicated and various, and the reasons causing the psychological problems are multifaceted. They mainly includes the social influence, the policy and measure of the subsidy the teachers' level, the schoolmate relations, the individual cognition and the family situation and so on. Most of the secondary vocational school students think that social prejudice, wrong cognition, interpersonal interaction difficulties and other factors have a greater impact on them. Head teachers have no psychological basis. Psychological teachers in schools think that Bi-disadvantaged students generally have poor psychological inferiority, wrong cognition, sensitive, mood fluctuations and other issues.

\section{Research conclusion}

\subsection{The health level of the BSISVS psychological is generally low.}

In comparison with ordinary vocational students, Bi disadvantaged Students' psychological health level is generally low. Due to the double pressure of economic and academic they are faced with, the psychological pressure Bi disadvantaged Students bear is heavier, and they are more vulnerable to psychological conflict. Providing that they do not have a good grooming and change, it is likely to further develop psychological illness or mental illness.

\subsection{The Bi-disadvantaged student's mental health having serious symptoms reflects some of the psychological characteristics of vocational Bi-disadvantaged students.}

Because of the economic and learning difficulties, BSISVS have different degrees of inferiority, which make them have the following characteristics: (1)They are more sensitive and emotional, pay more attention to their inner conflicts, care about others evaluation to them. (2) The wrong understanding and attribution of poverty lead to the fact that Bi-disadvantaged students are more likely to be self-denial and inferiority.(3) their defense mechanisms is higher. (4)Their achievement motivation is so high, that they try to prove themselves by learning, but the big gap between ideal and reality, leads to Bi-disadvantaged students being more prone to have the feeling of anxiety, depression and other negative emotions.(5) Academic failure, and economic pressure make Bi-disadvantaged students be more easily to have a sense of self frustration, pessimism and hopelessness.

\subsection{The economic difficulties, learning difficulties will affect the poor students' Psychology.}

The impacts of economic difficulties are as follows: first, the students with economic difficulties are given great expectations, which increase their psychological burden. After entering the school, the gap between ideal and reality will affect Bi-disadvantaged students' self-affirmation and lead to a sense of inferiority. Second, students with financial difficulties live a life short of life during their studies. The gap between the rich and the poor students also easily leads to Bi-disadvantaged students' inferiority and sensitive, which makes them difficult to integrate into social groups. Third, due to economic difficulties, many parents of students living struggling back and forth, lack of communication and interaction with their children. Many Bi-disadvantaged students are introverted and lack of sense of security. Four, some schools blindly fund the students, which the students' dependence and unearned psychology, leading to the lack of self-esteem, self-reliance and other qualities.

The impacts of academic difficulties are as follows: Due to academic difficulties, some Bi-disadvantaged students are abandoned by their teachers, which makes them backward and has no urge to make progress. Many outstanding students with good conditions laugh at the Bi-disadvantaged students, which can make them more backward in communication and more sensitive. Because of economic difficulties, hoping a good performance in learning after entering the school, high achievement motivation leads to excessive pressure. Once they failed, they will be more anxious and excessive anxiety, and will affect their learning efficiency, resulting in vicious spiral. The above negative emotions, the wrong cognition have not been well adjusted and changed, it is likely to further develop psychological illness or mental illness. 


\subsection{The intervention measures for the Bi-disadvantaged students' psychological problems.}

The social support and guidance of public opinion education needs the care, support and participation of the whole society. The government should strengthen the leadership and guidance of vocational education, standardize the running of schools, increase the investment and construction, and provide the impetus and guarantee for the reform of secondary vocational school. In view of the existence of the social prejudice and discrimination against vocational, how to better understand and treat the students. It not only need the teachers, but also the communities. We should increase the effects of publicity and education to guide the public opinion to give more respect, understanding and care for secondary vocational students.

Improve the funding system, improve the way of funding. Economic difficulties are one of the important reasons that Bi-disadvantaged students have psychological problems. In the implementation of providing capital subsidies Bi-disadvantaged students on capital subsidies, subsidized students' psychological state cannot be ignored. Blindly subsidies are not only easy to let them have a sense of inferiority but also breed the psychological dependence of them. Providing opportunities for more often than simply contributions is more conducive to the healthy development of the Bi disadvantaged students. It is widely suggested that they go to participate in their own professional practice to realize their value in the work. And it cannot only solve part of their living problem, but also contribute to improve their work ability, interpersonal skills and individual quality. It not only helps them understand themselves better and embody their self-value, but also enhance its self-confidence and sense of social responsibility.

Improve the quality of teachers and carry out targeted education for Bi-disadvantaged students. Strengthen the construction of teaching staff, and improve the psychological teachers, professional teachers and class teachers' psychological health education through various channels, to provide important support for the work of Bi disadvantaged student's psychological poverty. Class teacher should know and grasp Bi disadvantaged students' psychological state in time, enlighten the students with bad mood timely. Because of inferiority and other ideological concerns, Bi disadvantaged students are afraid to be on intimate terms with others. Class teachers should pay more attention to them, take the initiative to be close to them and care about their living situation; strengthen the education for understanding of poverty through various forms, and help Bi disadvantaged students establish a correct outlook on life and wealth. At the same time, class teachers can obtain of life and mind of Bi-disadvantaged students with the help of class cadres and discover the students with the existence of negative emotions timely to do the ideological dredge work for them.

\section{Conclusion}

Encourage students to help each other and create a good learning atmosphere. School is another big family for students. Harmonious relationship will have a huge impact on the poor students' psychology. It is important to encourage students to help each other, and create a good atmosphere for study and life; guide students to put forward and solve the problems in time when they encounter difficulties. Don't hurt others with language attack and physical assault. It is necessary to regulate various contradictions among the students because of different living environment and family environment to prevent the Bi-disadvantaged students for becoming more introverted, even evolved into a mental illness.

Secondary vocational schools should be able to provide various kinds of pertinent mental health education for secondary vocational school psychologically poor students. School should set up counseling center for students with psychological distress to provide professional help for them. Student should be encouraged to take the initiative to seek help. School psychological centers also should actively provide group counseling or individual counseling and other forms of help to Bi-disadvantaged students, targeted recruitment and take the initiative to invite the group to participate in the activities of mental health education. To timely divert some of the more introverted and depressed mood of the Bi-disadvantaged students, these measures can prevent them from the 
worst psychological direction; to help the poor students bear weak ability to enhance their ability to bear frustration; the result is not ideal or low self-confidence and psychologically poor students, to master their dynamic contact and patient psychological counseling to help them, teach them to a correct view of the situation and experience, enhance the ability of endurance in the face of difficulties, help them cultivate a positive outlook on life.

\section{Acknowledgements}

The achievement of" Weaving the sun and mind, achieving the beautiful dream--"The heart of the bay" of college students mental health education workstation" instructor boutique project 2016 in WTU.

\section{References}

[1]. Ministry of education "secondary vocational school students' psychological health education guidelines", July 2004.

[2]. Wang Maomin. Analysis of secondary vocational school students' psychological characteristics and Educational Countermeasures [J]. Science and technology information (Scientific Research), 2007, 34:592-593.

[3]. Haiping Zhi, Xishun Zhang. Occupation college "Bi-disadvantaged students" rational thinking on the problem of $[\mathrm{J}]$. Chinese adult education, 2006, 05:68-69.

[4]. Xiuqin Cao. Causes and Countermeasures of secondary vocational school students' mental health problems [J]. Industry and Technology Forum, 2006, 05:120-121.

[5]. Weiguang Yang. New western reason analysis and Countermeasure of [J]. College "double storm" phenomenon highlights (second half), 2010, 04:158-159.

[6]. Xiaoxue Dai, Tingting Huang. Analysis and Countermeasures of mental health status of secondary vocational school students [J]. Contemporary vocational education, 2010, 11:55-57. 